\title{
Survey of methods and statistical models used in the analysis of occupational cohort studies
}

\author{
Peter W Callas, Harris Pastides, David W Hosmer
}

\begin{abstract}
Objectives-This survey was conducted to determine the frequency with which different data analysis techniques are being used in occupational cohort studies. Of particular interest was the relative use of external and internal comparison groups, and the choice of multivariable model.

Methods-Occupational cohort studies published in 1990-91 were located with Medline and Index Medicus, and the contents of several relevant journals were systematically reviewed. Each study was categorised by the methods of external or internal comparisons performed.
\end{abstract}

Results-Of 200 occupational cohort studies identified, $104(52 \%)$ conducted only external comparisons, 46 (23\%) conducted only internal, and $50(25 \%)$ presented both. Of those that used an external referent population, about two thirds used a national standard. 40 of the studies that performed internal comparisons fitted multivariable models, with use divided about equally between proportional hazards regression, Poisson regression, and logistic regression.

Discussion-The finding that logistic regression is used quite commonly, even though it does not directly model time dependent data of the type frequently encountered in occupational cohort studies, was suprising. The reasons why investigators choose from among the available statistical and modelling techniques are likely to include familiarity, ease of use, restrictions in study population characteristics, especially study size, and others. Authors should be encouraged to be more explicit about the statistical methods used in the analysis of occupational cohort studies, as well as whether important assumptions about their data have been evaluated.

(Occup Environ Med 1994;51:649-655)

Keywords: occupational cohort .. studies, statistical analysis

Occupational cohort studies use the same basic design intrinsic to all epidemiological cohort studies: a group of subjects free from the outcome of interest is followed over time, and the rates at which the outcome develops are compared for cohort members possessing various levels of risk characteristics. To a certain extent, however, the analytical approaches to occupational and non-occupational cohort research have evolved somewhat differently. Non-occupational cohort studies (such as the Framingham heart study ${ }^{1}$ ) involve an internal comparison of disease rates among the exposed and unexposed subjects, whereas estimation of risk in the occupational setting has traditionally been relative to groups external to the study, comparing the rate of outcome of cohort members to, say, the rates in a national or regional population.

As is widely recognised, there can be problems in relying only on external comparisons. ${ }^{2}$ Standardised morbidity or mortality ratios (SMRs) are computed by comparing the observed number of deaths, or other outcome of interest, in the cohort with the number expected based on national or other population rates. Usually the source of standard rates for an SMR is external to the cohort, although occasionally an internal source is used. In this paper the standard is assumed to be external except where otherwise stated.

Age and sex differences between the cohort and the standard population are accounted for in construction of the SMR, but most other demographic, social, and economic potential confounders are not. Also, workers in general are healthier than the population as a whole ${ }^{34}$; however, the degree of bias from this healthy worker effect is usually not estimable with any certainty. Also, SMRs for different cohorts are not strictly comparable with each other, with the amount of bias dependent on the magnitude of differences in the age structures of the cohorts.

Internal comparisons are the comparison of risks between cohort members with different levels of exposure. Although the precision of internally derived relative risks is generally lower than SMRs based on external standard rates, the validity is usually higher, which is almost always the more important consideration. ${ }^{6}$ Hence, the use of an internal comparison group is often the preferable method.

Due to the complex nature of most relations between risk factors and disease some account for the effects of various covariates is extremely important in the correct interpretation of the study results. Recent advances in computer software have resulted in multivariable modelling becoming a standard method for adjustment of confounders in epidemiological research. Three statistical methods commonly used in analysis of cohort data are proportional hazards 
regression, ${ }^{57}$ Poisson regression, ${ }^{89}$ and logistic regression. ${ }^{10}$

The proportional hazards model is generally considered to be the method of choice for data with varying follow up time, but may be too complex and expensive to use easily. " Poisson regression will often give results very similar to those of proportional hazards regression, and in general uses much less computer time to fit, but software data setup requirements can be a problem. ${ }^{12}$ Logistic regression is less well suited than the other two for cohort data because it does not inherently account for possible different lengths of follow up for each cohort member or for changes in values of variables (such as age or cumulative exposure) over time. Nevertheless, it is often used in cohort study analysis because in most situations it is easier and less expensive than the proportional hazards or Poisson models.

There seems to be increasing use of internal comparisons and statistical modelling in analysis of occupational cohort data. The survey reported in this paper was undertaken to assess the relative frequencies with which external and internal control groups are used in occupational cohort studies, and to examine choice of model in studies that use multivariable internal comparisons. To determine the extent to which different analytical techniques are being used for such data, we have reviewed occupational cohort studies published over a recent two year span.

\section{Methods}

A systematic search was conducted to identify occupational cohort studies published in $\mathbf{1 9 9 0}$ and 1991. Published studies from these years were identified through a computerised Medline search, a review of Index Medicus, and a review of contents of journals likely to publish occupational cohort studies, including the seven journals with the largest number of such studies listed in the Medline search $(\mathrm{Br} \mathcal{F}$ Ind Med, Am $\mathcal{f}$ Ind Med, Scand $\mathcal{f}$ Work Environ Health, $\mathcal{F}$ Occup Med, Int Arch Occup Environ Health, Arch Environ Health, and Am $\mathcal{F}$ Epidemiol). The search was limited to papers published in English.

A study was classified as occupational in nature if it primarily evaluated an occupationally acquired exposure. Thus, included was an investigation that examined the association between occupation in general and mortality, with the cohort consisting of all "economically active men in Denmark aged 20-64 years by November 9th 1970,"13 whereas a study that for convenience used an occupational cohort (employees of three pharmaceutical companies in Basel, Switzerland) but examined nonoccupational exposures (plasma concentrations of vitamins $\mathrm{A}, \mathrm{C}, \mathrm{E}$, and carotene $v$ cancer mortality) ${ }^{14}$ was excluded.

Cohort studies were defined as those in which subjects were classified by their risks and then followed up over time to determine an outcome. Follow up could be either prospective or historical. Because the focus was on cohort methods of analysis, reports that analysed only nested case-control studies were excluded, as were those that computed only proportionate mortality ratios or used only matched subjects (such as twins).

In cohort studies, the outcome can be either time to occurrence of an event or just presence or absence of the event itself. Outcomes of interest in this review were one time events such as overall or cause specific mortality, cancer incidence, development of coronary heart disease, infection with human immunodeficiency virus, adverse pregnancy outcome, disability, etc. Some investigations concerning outcomes that could occur more than once-for example, back injury resulting in lost work time ${ }^{15}$ - were included if the analysis concentrated on the first time the event occurred or if the outcome was defined as ever or never. Studies of only continuous physiological outcomes, such as measures of respiratory function, were not included.

Studies were first categorised into broad groups based on whether they used an external or internal comparison group, or both, in the analysis. The next step was to classify studies by the methods of external or internal comparison that were performed.

Sometimes the comparison group was not easily categorised as external or internal. In these situations we used a certain degree of judgement. We defined internal controls as non-exposed (or low exposure) subjects with generally similar levels of record review, interviews, measurement of potential confounders, etc, as were available for the exposed cohort. Thus, in a study of respiratory disease among workers in a cement factory in Aalborg, Denmark, ${ }^{16}$ the comparison group of a sample of other Aalborg residents who did not work in cement factories was considered internal, because these people were also surveyed for smoking, lung function, and other relevant factors.

Standardised rate ratios (SRRs) are used to make internal comparisons between subgroups of the cohort, with direct adjustment of the rates with the entire cohort as the standard population. Unlike SMRs, for SRRs direct comparisons can validly be made between cohort members; therefore, studies with SRRs were classified as internal comparisons.

In instances where the same cohort appeared in more than one published paper, each report was counted separately. Usually, different risk factors or outcomes were being examined. Sometimes one publication reported on the full cohort whereas another focused on only a subset. In one instance separate analysis of two different cohorts appeared in the same paper. ${ }^{17}$ These were counted as distinct studies.

Classification of the type of analysis used was generally based on what was stated in the methods section of a paper, although examination of the results often helped clarify exactly what was done. Sometimes a study was classified by the use of a particular analytical method even though the paper did not directly name it. This was usually because of 
Table 1 fournals that published occupational cohort studies in 1990-91

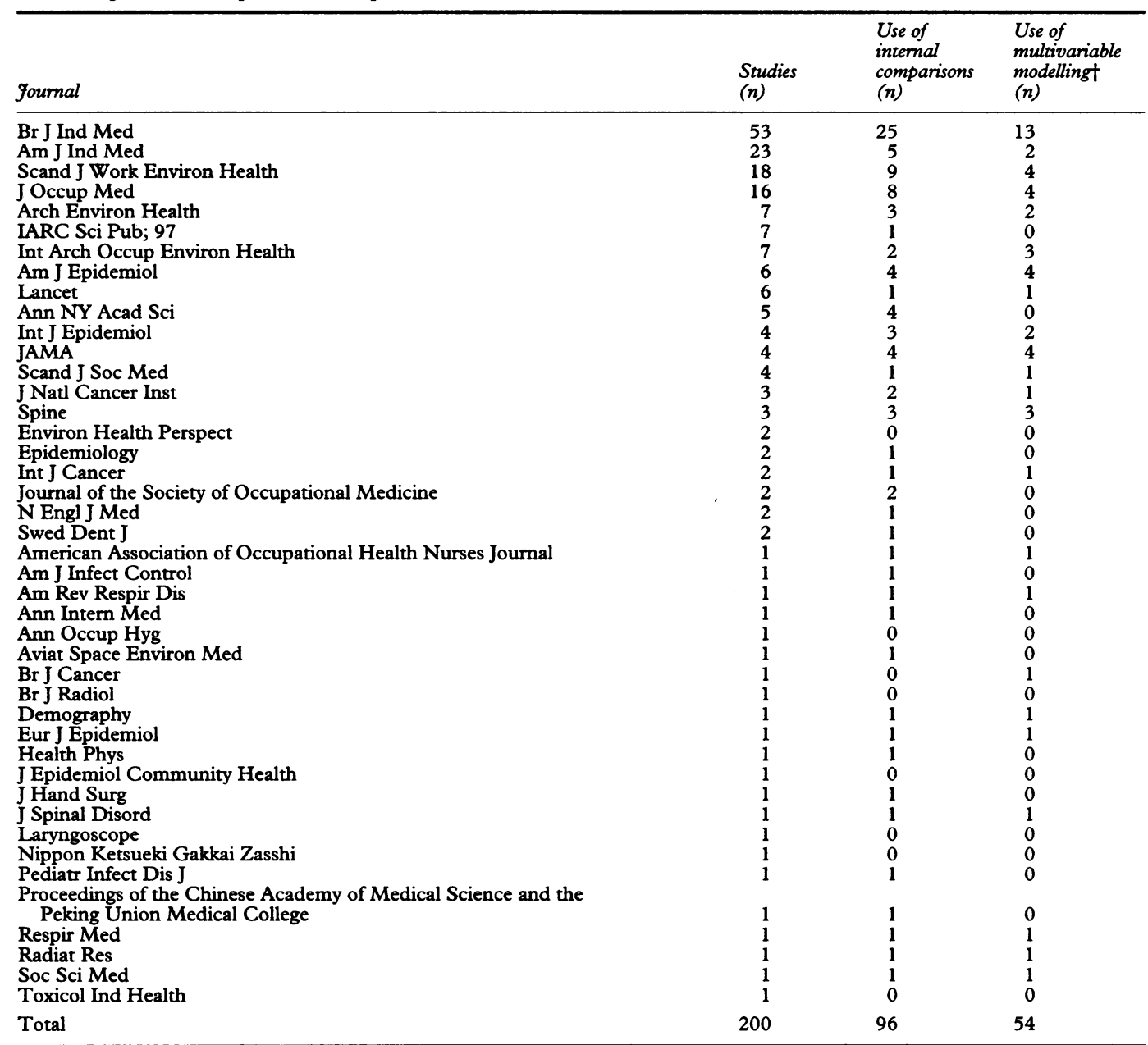

†Includes Poisson regression with external standard population.

either differences in terminology (a study that reported results as standardised incidence ratios would be classified under SMR) or use that could be inferred. In one report, for example, directly age adjusted mortality rates were computed and compared for subgroups of a cohort with the person-year distribution of the entire cohort as the standard. ${ }^{18} \mathrm{We}$ classified this as a standardised rate ratio analysis even though it was not stated as such in the paper. (SMRs were also computed in this study.)

\section{Results}

A total of 200 occupational cohort studies published in 1990-91 were identified. Of these, $104(52 \%)$ conducted only external comparisons, $46(23 \%)$ conducted only internal, and $50(25 \%)$ conducted both. Table 1 lists the journals in which the studies were published, along with a breakdown of the number of studies that used internal comparisons and number that used multivariable modelling.

All 154 studies that used an external reference group computed standardised morbidity or mortality ratios. Table 2 shows the sources of the rates of a standard population used in these studies. Over half used only a national standard, and another $15 \%$ used national and state or regional rates. Thirteen studies from Scandinavian countries took advantage of linkages between occupational information in their census records and cancer registry and mortality data to get reference rates specific to employed people, which helps mitigate the healthy worker effect.

Besides the factors adjusted through standardisation (generally age, sex, and year), 14 of the studies that computed SMRs presented additional external analyses that controlled for other potential confounders. These studies used an SMR type of Poisson regression, in which the rates of the external standard population were incorporated into the model as the baseline, rather than having the baseline rates estimated from the cohort as is typical in the

Table 2 Standard populations used in SMR analyses

\begin{tabular}{lc}
\hline Standard population & Studies $(n(\%))$ \\
\hline National only & $82(53 \cdot 2)$ \\
State or province only & $11(7 \cdot 1)$ \\
Regional or county only & $16(10 \cdot 4)$ \\
National and state & $10(6 \cdot 5)$ \\
National and regional & $12(7 \cdot 8)$ \\
National, state, and regional & $2(1 \cdot 3)$ \\
Employed persons only in country or & $13(8 \cdot 4)$ \\
region & $6(3 \cdot 9)$ \\
Other & $2(1 \cdot 3)$ \\
Not explicitly stated & $154(100)$ \\
Total & \\
\hline
\end{tabular}


Table 3 Types of internal comparisons performed

\begin{tabular}{lc}
\hline Internal method of comparison & Studies $(n)$ \\
\hline Multivariable modeling: & 11 \\
Proportional hazards & 13 \\
Poisson regression & 13 \\
Logistic regression & 1 \\
Proportional hazards and Poisson & 2 \\
Proportional hazards and logistic & 2 \\
Life table analysis & 11 \\
Stratified or adjusted relative risk & 9 \\
Unadjusted relative risk & 10 \\
Nested case-control & 1 \\
Matched cohort analysis & 8 \\
Standardised rate ratios & 9 \\
Standardised mortality ratios with & \\
internal standard population & 6 \\
Descriptive comparisons only & 96 \\
Total & \\
\hline
\end{tabular}

Poisson regression modelling with only internal comparisons.

One investigation which used an external reference population computed both SMRs and an additive measure based on the difference between the observed and expected numbers used to calculate the SMRs. ${ }^{19}$

Table 3 presents the types of analysis performed in the 96 studies that used internal comparisons. The listings are mutually exclusive-that is, each study is counted in the table only once-if both unadjusted relative risks and relative risks obtained from Poisson regression were reported, the study would be classified under Poisson regression.

Table 3 shows that internal multivariable modelling was conducted in 40 of the 200 studies $(20 \%)$. Use of proportional hazards, Poisson, and logistic regression was divided about equally among these studies. Although it was often not explicitly stated, the multiplicative forms of the models were apparently usually used as results were generally presented as estimates of hazard ratios, rate ratios, or odds ratios. One investigation used a linear relative risk model. ${ }^{20}$ In another study, ${ }^{21}$ both multiplicative and additive Poisson models were tried; because the multiplicative form had a better fit, only these findings were shown. The study that performed both proportional hazards and Poisson regression ${ }^{22}$ also fits the more general Breslow-Storer relative risk model, which allows for estimation of whether the independent variables act multiplicatively, additively, or otherwise. ${ }^{23}$ (Also, non-multiplicative models were examined in two of the reports that used Poisson regression with an external standard. ${ }^{24}{ }^{25}$ )

Of the studies that used proportional hazards regression, two used parametric forms of the baseline hazard-one Weibull ${ }^{26}$ and one Gompertz. ${ }^{27}$ The rest apparently treated the baseline hazard non-parametrically, with the technique originally described by Cox. ${ }^{7}$ Four of the papers that used the proportional hazards model were actually different analyses of the same cohort. ${ }^{28-31}$

In three of the studies that performed logistic regression, ${ }^{32-34}$ the unit of observation was a person-time interval rather than an individual subject, which is the usual method. With person-time units elements of time can be incorporated into the logistic model. This approach is discussed further in the discussion section.

It is of interest to note that, of the studies that conducted internal comparisons through multivariable modelling, 14 (35\%) also computed SMRs. In some instances, the external comparisons were actually the main focus of the analysis, with modelling performed only to specifically examine one aspect of the study.

Table 3 shows investigations that used nested case-control or matched cohort analysis as the only methods of internal comparisons, but analyses of SMRs were also used in these studies.

Nine studies that computed SMRs used an internal group as the source of the standard rates. For example, in a report by Tsai et al ${ }^{35}$ the expected number of events that occurred among chemical workers exposed to epichlorohydrin were based on outcome rates of workers at the same plants who were not exposed to this chemical. Such studies are listed as internal SMR studies (table 3). (These should be distinguished from ones that simply compared, say, nationally standardised SMRs for different subgroups of the cohort, which were not considered to be internal comparisons.)

\section{Discussion}

Although many of the papers we reviewed were relatively clear in their statement of methods used, quite a few lacked important methodological details, including the number of subjects in the cohort, the length of follow up, and the source of standard population used in the computation of SMRs. Assumptions underlying the statistical techniques used were most often not stated, nor was there usually any mention of whether these assumptions were checked. Also, studies would occasionally report that an analytical method was used, but never present the accompanying results.

The main conclusions of this survey are: that SMRs continue to dominate as the principal analytical tool in occupational cohort studies; and that no predominant choice for multivariable modelling has emerged from among the alternatives.

\section{USE OF SMRS}

We found that over $75 \%$ of occupational cohort studies published in 1990-91 reported SMRs, and about half reported only SMRs. Furthermore, most studies that performed some type of internal comparisons also presented SMRs. This is similar to a small survey of 20 occupational cohort studies of cancer that were published in 1982 in $A m f$ Epidemiol, Br $\mathcal{F}$ Ind Med, and $\mathcal{F}$ Occup Med. Saracci and Johnson ${ }^{36}$ found that 19 of the 20 used the SMR as the primary analytical technique for the control of time dependent variables such as age.

There are undoubtedly several reasons for the continued predilection for SMR analyses. Sometimes, because of the data source, external comparisons are the only possibility. In an 
investigation of mortality among newspaper printers exposed to low levels of lead, records of the New York Typographical Union No 6 were used to identify all male members employed at two New York City newspapers. ${ }^{37}$ The SMRs were computed to compare the mortality experience of the cohort to that of the entire New York City male population because data for differentiating level of exposure among the printers were unavailable. On the other hand, some studies that have quantitative or qualitative exposure estimates, or have an unexposed comparison group, still compute SMRs exclusively. The reasons the available data were not used more fully were usually not stated. One possible reason is small study size that would adversely affect analyses with internal comparison groups. For example, in an historical cohort study of cancer mortality in laboratory workers, Belli et al had access to a non-exposed group who worked in the same building, yet only SMRs were presented. ${ }^{38}$ This was most likely because just eight deaths from cancer occurred among the 345 non-exposed workers over a 30 year follow up period.

Another reason for continued use of SMRs is likely to be the greater effort required to assemble the required information from a comparison group, even when such a group might be available. For example, a study of German workers exposed to dioxin specifically mentioned that they did not use an internal control group because it would be very time consuming and difficult to assemble and follow up an unexposed cohort (especially given the laws on access to data in Germany), and because national death rates are a more stable source of comparison data. ${ }^{39}$

We suspect that another reason, however, is the comfort level that investigators, and perhaps readers, of occupational studies have with SMRs. This will possibly change as modelling techniques become more widely taught and subsequently used.

Relating to the choice of comparison populations in SMR studies, we found that most studies that used SMR analyses used national rates for computing the expected number of events in the cohort. This should not be surprising given the generally greater availability of national vital statistics coupled with the fact that a large population will have more stable rates than a smaller one. Yet a national population is usually less representative of the population from which the cohort was derived in terms of the prevalence of exposure to a wide range of potentially confounding variables. In recognition of this, three investigations that used all of England and Wales as the standard population used "correction factors" to adjust for the known differences between rates in the local areas that the workers were from and the rates for the entire country. ${ }^{40-42}$

A disadvantage of a very small comparison area, such as a region closely surrounding a factory under study, is that the cohort itself could make up a sizable proportion of the standard population, which would bias the SMRs toward 100. Also, the usual test of sig- nificance for SMRs is based on the assumptions that the observed number of events follow a Poisson distribution and the rates in the standard population are fixed. ${ }^{11}$ This assumption may be violated when a small group is used as the source of standard rates, although there are alternative tests available.

A few of the studies that computed SMRs adjusted for multiple confounders through Poisson regression, with the external population used as the source of the baseline rates in the model. For discussions of the SMR Poisson model, see Breslow ${ }^{43}$ and Frome et al. ${ }^{44}$ Such an approach is also possible with the proportional hazards model, ${ }^{56}$ but we found no instances of this.

\section{USE OF MODELLING}

When internal comparisons were performed with regression modelling, proportional hazards and Poisson regression were found to be used about equally. These two models give very similar results in most circumstances, ${ }^{511}$ so choice between them is probably based on familiarity and ease of use in a given situation, as well as the availability of computer software.

Quite surprisingly, logistic regression was used as frequently as the proportional hazards and Poisson models, even though it does not directly model follow up time. It has been shown that the results from the logistic model will closely approximate those from the proportional hazards model when follow up time is short, the outcome is rare, the relative risks associated with the independent variables in the model are not large, and the underlying hazard rate is constant. ${ }^{45-49}$ Unfortunately, the degree of divergence when these conditions are not met has not been well studied.

Three studies fit the logistic model with data in the form of person-time intervals rather than in the usual person format. This approach is accomplished by dividing the follow up period into intervals, and the number of subjects at risk and outcome events in each interval are counted and summed across intervals. The logistic model is applied to the summed data. By doing this, between subject differences in follow up time can be incorporated into the analysis by subjects who only contributed person-time information to the data for as long as they are under observation, and within subject variations in covariate values over time can be accounted for by the values of variables for an individual being allowed to change from one person-time interval to the next. Use of person-time at risk data is essentially the method suggested as a way to use logistic software to estimate Poisson regression ${ }^{50}$ and is very similar to several modified versions of logistic regression that have been introduced for analysis of cohort data. ${ }^{491-56}$ As software for Poisson regression has become more widely available, there is probably little advantage in a logistic approach. ${ }^{57}$

FUTURE OF OCCUPATIONAL COHORT ANALYSES For the reasons given above, the continued 
use of SMR analyses in occupational cohort studies seems certain. This implies that the associated problems of potential selection bias, including the healthy worker effect, and potential confounding will need to be rectified by the use of adjunct techniques such as stratification. What is less clear is whether investigators will, or should, continue to calculate SMRs in situations where multivariable modelling or other internal comparisons are possible.

A related question is whether the choice of the multivariable model will become more standardised in the future. The key to the answer probably lies in whether we shall gain a fuller understanding of the relative performance of the proportional hazards, Poisson, and logistic models as applied in the analysis of cohort data. Although the underlying theoretical interrelations between these three models are well known, ${ }^{5}$ this has not always led to clear decisions for selecting which to use in practice. They can often give different results when applied to the same set of data. ${ }^{11}$ Specific areas that need to be considered include the relative performance with respect to the following: statistical criteria for accuracy of model parameters such as bias and mean squared error under varying situations-for example, when outcomes are common or rare, when follow up is long or short, etc; precision (width of the estimated confidence intervals); efficiency under situations of modest study size and when data are thinly distributed; and others. We are conducting some work in this area, which may help to develop specific recommendations.

Models other than the multiplicative proportional hazards, Poisson, and logistic techniques were found to be rarely used in analysis of occupational cohort data. This is probably due to lack of familiarity, lack of software, and difficulties in epidemiological interpretation of model coefficients. As these difficulties are overcome we may see more use of different models such as additive; more general models that include multiplicative as a special case, such as those proposed by Breslow and Storer ${ }^{23}$ and Moolgavkar and Venzon ${ }^{58}$; and models hypothesised for specific biological pathways, such as the Armitage-Doll multistage model of carcinogenesis. ${ }^{59} 60$

Finally, a recommendation that can confidently be made is for improvement in the reporting of methods and issues related to analysis in occupational studies. Peer reviewers and journal editors should require a full report of the techniques used, as well as any important assumptions about the data. Greenland has made a similar recommendation. ${ }^{61}$ There continues to be deficiency in the provision of relevant details that would help readers to interpret authors' conclusions in fuller light of the statistical tools used.

1 Dawber TR, Meadors GF, Moore FE. Epidemiological approaches to heart disease: the Framingham study. Am f Public Health 1951;41:279-86.

2 Liddell FDK. The development of cohort studies in epidemiology: a review. 7 Clin Epidemiol 1988;41:1217-37.
3 Fox AJ, Collier PF. Low mortality rates in industrial cohort studies due to selection for work and survival in cohort studies due to selection for work and survival in the industry. British fourma

4 McMichael AJ. Standardized mortality ratios and the "healthy worker effect": scratching beneath the surface. f Occup Med 1976;18:165-8.

5 Breslow NE, Day NE. Statistical methods in cancer research. Vol II: the design and analysis of cohort studies. Lyon: International Agency for Research on Cancer, 1987. (IARC Sci Publ No 82.)

6 Breslow NE, Lubin JH, Marek P, Langholz B. Multiplicative models and cohort analysis. fournal of the American Statistical Association 1983;78:1-12

7 Cox DR. Regression models and life-tables. Fournal of the Royal Statistical Saciety Series B 1972;34:187-202.

8 Frome EL. The analysis of rates using Poisson regression models. Biometrics 1983;39:665-74.

9 Frome EL, Checkoway H. Use of Poisson regression models in estimating incidence rates and ratios. $A m \mathcal{F}$ Epidemiol 1985;121:309-23.

10 Hosmer DW, Lemeshow S. Applied logistic regression. New York: John Wiley, 1989.

11 Checkoway H, Pearce NE, Crawford-Brown DJ. Research methods in occupational epidemiology. New York: Oxford University Press, 1989

12 Clayton D. The analysis of event history data: a review of progress and outstanding problems. Stat Med 1988; 7:819-41.

13 Tüchsen F, Zebitz U. Work and "lifestyle" in occupational mortality in Denmark. Scand $f$ Soc Med 1990;18: 179-83.

14 Stähelin HB, Gey KF, Eichholzer M, Lüdin E, Bernasconi F, Thurneysen J, Brubacher G. Plasma antioxidant vitamins and subsequent cancer mortality in the 12-year follow-up of the prospective Basel Study. Am $\mathcal{f}$ Epidemiol 1991;133:766-75.

15 Boshuizen HC, Hulshof CTJ, Bongers PM. Long-term sick leave and disability pensioning due to back disorders of tractor drivers exposed to whole-body vibration. Int Arch Occup Environ Health 1990;62:117-22.

16 Vesbo J, Rasmussen FV. Long-term exposure to cement dust and later hospitalization due to respiratory disease. dust and later hospitalization due to respiratory

17 You X-Y, Chen J-G, Hu Y-N. Studies on the relation between bladder cancer and benzidine or its derived dyes in Shanghai. Br F Ind Med 1990;47:544-52.

18 Macaluso $M$, Delzell $E$, Cole $P$, Wongsrichanalai $C$, Cowles S. Validity of a mortality study based on a corporate health surveillance system. $\mathcal{f}$ Occup Med 1991;33: $1180-6$.

19 Walker AM, Cohen AJ, Loughlin JE, Rothman KJ, DeFonso LR. Mortality from cancer of the colon or rectum among workers exposed to ethyl acrylate and methyl methacrylate. Scand $f$ Work Environ Health methyl methacry

20 Gilbert ES, Fry SA, Wiggs LD, Voelz GL, Cragle DL, Petersen GR. Methods for analyzing combined data from studies of workers exposed to low doses of radiation. Am F Epidemiol 1990;131:917-27.

21 Wigle DT, Semenciw RM, Wilkins K, Riedel D, Ritter L, Morrison HI, Mao Y. Mortality study of Canadian male farm operators: non-Hodgkin's lymphoma mortality and agricultural practices in Saskatchewan. $f$ Natl Cancer Inst 1990;82:575-82.

22 Hnizdo E, Sluis-Cremer GK. Silica exposure, silicosis, and lung cancer: a mortality study of South African gold miners. Br f Ind Med 1991;48:53-60.

23 Breslow NE, Storer BE. General relative risk functions for case-control studies. Am $\mathcal{E}$ Epidemiol 1985;122:149-62.

24 Hodgson JT, Jones RD. Mortality of a cohort of tin miners 1941-86. Br ₹ Ind Med 1990;47:665-76.

25 Piolatto G, Negri E, La Vecchia C, Pira E, Decarli A, Peto $J$. Bladder cancer mortality of workers exposed to aromatic amines: an updated analysis. Br $\mathcal{f}$ Cancer 1991; 63:457-9.

26 Kongerud J, Samuelsen SO. A longitudinal study of respiratory symptoms in aluminum potroom workers. $A m$ Rev Respir Dis 1991;144:10-6.

27 Moore DE, Hayward MD. Occupational careers and mortality of elderly men. Demography 1990;27:31-53.

28 Battié MC, Bigos SJ, Fisher LD, Spengler DM, Hansson TH, Nachemson AL, Wortley MD. Anthropometric and $\mathrm{TH}$, Nachemson AL, Wortley MD. Anthropometric and
clinical measures as predictors of back pain complaints in industry: a prospective study. $f$ Spinal Disord 1990;3: in industry:

29 Battié MC, Bigos SJ, Fisher LD, Spengler DM, Hansson TH, Nachemson AL, Wortley MD. The role of spinal flexibility in back pain complaints within industry: a prospective study. Spine 1990;15:768-73.

30 Bigos SJ, Battié MC, Spengler DM, Fisher LD, Fordyce WE, Hansson TH, et al. A prospective study of work perceptions and psychosocial factors affecting the report of back injury. Spine 1991;16:1-6.

31 Bigos SJ, Battié MC, Fisher LD. Methodology for evaluating predictive factors for the report of back injury. Spine 1991;16:669-70.

32 Bonde JP, Hansen KS, Levine RJ. Fertility among Danish male welders. Scand $₹$ Work Environ Health 1990;16: 315-22.

33 Coste J, Mandereau L, Pessione F, Bregu M, Faye C, Hemon D, Spira A. Lead-exposed workmen and fertility: a cohort study on 354 subjects. Eur $\mathcal{F}$ Epidemiol ity: a cohort

34 Hunting $\mathrm{KL}$, Matanoski GM, Larson M, Wolford $\mathbf{R}$. 
Solvent exposure and the risk of slips, trips, and falls among painters. Am F Ind Med 1991;20:353-70.

35 Tsai SP, Cowles SR, Tackett DL, Barclay MT, Ross CE Morbidity prevalence study of workers with potential exposure to epichlorohydrin. $\mathrm{Br}$ F Ind Med 1990;47: 392-9.

36 Saracci $R$, Johnson E. A note on the treatment of time in published cancer epidemiology studies. Foumal of Chronic Diseases 1987;40(suppl 2):77S-8S.

37 Michaels D, Zoloth SR, Stern FB. Does low-level lead exposure increase risk of death? A mortality study of newspaper printers. Int $\mathcal{f}$ Epidemiol 1991;20:978-83.

38 Belli S, Comba P, De Santis M, Grignoli M, Sasco AJ. Cancer mortality patterns among laboratory workers Cancer mortality patterns amo.

39 Zober A, Messerer P, Huber P. Thirty-four-year mortality follow-up of BASF employees exposed to 2,3,7,8-
TCDD after the 1953 accident. Int Arch Occup Environ TCDD after the 1953 act

40 Winter PD, Gardner MJ, Fletcher AC, Jones RD. A mortality follow-up study of pottery workers: preliminary findings on lung cancer. In: Simonato L, Fletcher AC, Saracci R, Thomas TL, eds. Occupational exposure to silica and cancer risk. Lyon: International Agency for Research on Cancer, 1990:83-94. (IARC Sci Publ No 97.)

41 Davies JM, Easton DF, Bidstrup PL. Mortality from respiratory cancer and other causes in United Kingdom chromate production workers. Br f Ind Med 1991;48: mate produc

42 Paddle GM, Osborn AJ, Parker GDJ. Mortality of employees in plants manufacturing 4,4'-bipyridyl. Scand $\mathcal{F}$ Work Environ Healch

43 Breslow N. Multivariate cohort analysis. National Cancer Institute Monographs 1985;67:149-56.

44 Frome EL, Cragle DL, McLain RW. Poisson regression analysis of the mortality among a cohort of World War II nuclear industry workers. Radiat Res 1990;123:138-52.

45 Green MS, Symons MJ. A comparison of the logistic risk function and the proportional hazards model in prospective epidemiologic studies. Fournal of Chronic Diseases 1983;36:715-23.

46 Annesi I, Moreau T. A comparison of the logistic risk function and the Cox's model in longitudinal studies (abstract). Bulletin Européan Physiopathologie Respiratoire 1985;21 (suppl):47K

47 Brenn T, Amesen E. Selecting risk factors: a comparison of discriminant analysis, logistic regression and Cox's regression model using data from the Tromsø Heart Study. Stat Med 1985;4:413-23.

48 Steenland $K$, Beaumont J, Hornung $R$. The use of regression analyses in a cohort mortality study of welders. Fournal of Chronic Diseases 1986;39:287-94.

49 Ingram DD, Kleinman JC. Empirical comparisons of proportional hazards and logistic regression models. Stat Med 1989;8:525-38.

50 SAS Institute Inc. SAS technical report $P-200$. SAS/STAT sofrware: CALIS and LOGISTIC procedures, release 6.04. Cary, NC: SAS Institute, 1990:224-5.

51 Thompson WA. On the treatment of grouped observations in life studies. Biometrics 1977;33:463-70.

$52 \mathrm{Wu} \mathrm{M}$, Ware JH. On the use of repeated measurements in regression analysis with dichotomous responses. regression analysis with
Biometrics 1979;35:513-21

53 Abbott RD. Logistic regression in survival analysis. $A m \mathcal{F}$ Epidemiol 1985;121:465-7

54 Cupples LA, D'Agostino RB, Anderson K, Kannel WB. Comparison of baseline and repeated measure covariate techniques in the Framingham Heart Study. Stat Med 1988;7:205-18.

55 Efron B. Logistic regression, survival analysis, and the Kaplan-Meier curve. Fournal of the American Statistical Association 1988;83:414-25.

56 D'Agostino RB, Lee M-L Belanger AJ, Cupples LA, Anderson $\mathrm{K}$, Kannel WB. Relation of pooled logistic regression to time dependent Cox regression analysis: the Framingham Heart Study. Stat Med 1990;9: the Fram

57 Mock P. Empirical comparisons of proportional hazards and logistic regression models [letter]. Stat Med 1990;9: 463-4.

58 Moolgavkar SH, Venzon DJ. General relative risk regression models for epidemiologic studies. Am $\mathcal{f}$ Epidemiol 1987;126:949-61.

59 Armitage P, Doll R. Stochastic models for carcinogenesis. In: Neyman J, ed. Proceedings of the fourth Berkeley symposium on mathematical statistics and probability. Vol IV. Berkeley, CA: University of California Press, 1961: 19-38.

60 Mazumdar S, Redmond CK, Costantino JP, Patwardhan RN, Zhou SYJ. Recent developments in the multistage modeling of cohort data for carcinogenic risk assessmodeling of cohort data for carcinogenic risk
ment. Environ Health Perspect 1991;90:271-7.

61 Greenland S. Modeling and variable selection in epidemiologic analysis. Am $\mathcal{F}$ Public Health 1989;79:340-9.

\section{Instructions to authors}

Three copies of all submissions should be sent to: The Editor, Occupational and Environmental Medicine, BMJ Publishing Group, BMA House, Tavistock Square, London WC1H 9JR, UK. All authors should sign the covering letter as evidence of consent to publication. Papers reporting results of studies on human subjects must be accompanied by a statement that the subjects gave written, informed consent and by evidence of approval from the appropriate ethics committee. These papers should conform to the principles outlined in the Declaration of Helsinki (BMF 1964; ii:177).
If requested, authors shall produce the data on which the manuscript is based, for examination by the Editor.

Authors are asked to submit with their manuscript the names and addresses of three people who they consider would be suitable independent reviewers. They will not necessarily be approached to review the paper.

Papers should include a structured abstract of not more than 300 words, under headings of Objectives, Methods, Results, and Conclusions. Please include up to three keywords or key terms to assist with indexing. 